\title{
DETERIORAÇÃO DE SEMENTES DE MAMONA ARMAZENADAS COM E SEM CASCA ( $\left.{ }^{(}\right)$
}

\author{
ANTONIO AUGUSTO DO LAGO $\left({ }^{2,6}\right)$, EDUARDO ZINK $\left({ }^{2}\right)$, ANGELO SAVY FILHO $\left({ }^{3,6}\right)$, \\ JOÃO PAULO FEIJÃO TEIXEIRA $\left({ }^{4,6}\right)$, e NICOLAU VICTORIO BANZATTO $\left({ }^{5}\right)$
}

\begin{abstract}
RESUMO
Sementes de mamona foram armazenadas com casca (sem danos mecânicos provenientes de descasque) e sem casca (método convencional) por um período de 36 meses, em condiçoes nđo controladas de armazém, na região de Campinas (SP). A gradual deterioraçđo das sementes foi avaliada por testes de germinaçato a cada três meses e por análise do teor de óleo e ácidos graxos livres aos 36 meses. A deterioração das sementes descascadas mecanicamente e assim armazenadas foi mais rápida do que a daquelas armazenadas com casca, principalmente após o primeiro ano. Sementes com e sem casca do cultivar Campinas apresentaram, depois de 0,6,12, 24 e 36 meses de armazenamento, germinação de, respectivamente, 83 e 82\%, 82 e $80 \%, 79$ e $69 \%, 65$ e $23 \%$ e 51 e $0 \%$. Após os mesmos perfodos de armazenamento, para o cultivar Guarani, obteve-se para sementes com e sem casca germinação de, respectivamente, 85 e $82 \%, 81$ e $75 \%, 76$ e $62 \%, 68$ e $13 \%$ e 38 e 0\%. Decorridos 36 meses de armazenamento, os teores de ácidos graxos livres para sementes com casca dos cultivares Campinas e Guarani foram respectivamente 1,6 e 3,2\%, e, para sementes sem casca dos mesmos cultivares, 63,0 e $64,8 \%$.
\end{abstract}

Termos de indexaçđo: deterioraçđo, armazenamento, sementes, mamona, cultivares Campinas e Guarani.

\footnotetext{
(1) Recebido para publicação em 24 de agosto de 1983.

$\left({ }^{2}\right)$ Seção de Sementes, Instituto Agronómico (IAC). Caixa Postal 28, 13100 - Campinas (SP).

(3) Seçāo de Oleaginosas, IAC.

$\left({ }^{4}\right)$ Seção de Fitoquímica, IAC.

(5) Divisão de Biologia Fitotécnica, IAC.

(6) Com bolsa de suplementação do CNPq.
} 


\section{INTRODUÇÃO}

Entre os diversos fatores que diminuem a longevidade de sementes durante o armazenamento, destacam-se os danos mecânicos na operação de batedura ou descasque. Duas importantes características afetam a intensidade de tais danos: a estrutura das sementes e a resistência do fruto à separação das mesmas (JUSTICE \& BASS, 1978).

De acordo com MOORE (1972), sementes danificadas têm menor longevidade que sementes intactas, e o problema é agravado por invasão de fungos pelas rachaduras do tegumento; injúrias pequenas e pouco visíveis podem não causar imediata perda de viabilidade, mas podem tornar-se críticas à medida que a semente envelhece.

ZINK (1966) e POPINIGIS (1972) demonstraram os efeitos negativos de danos mecânicos na germinação de sementes de soja, seja de forma imediata, seja no armazenamento. Efeitos semelhantes foram observados no descasque mecânico de sementes de amendoim por BACCHI \& CANECCHIO FILHO (1954), ZINK et alii (1962) e BASKIN \& DELOUCHE (1971).

Sementes de mamona dos cultivares indeiscentes sao particularmente sensíveis a danos durante o descasque mecânico devido a: $(a)$ embrião e endosperma relativamente delicados; $(b)$ radicula muito próxima da superfície da semente; $(c)$ tegumento quebradiço e $(d)$ frutos com certa resistência ao descasque. Tais danos se manifestam sob as formas de esmagamento do embrião ou suas partes, abrasão, rachaduras, quebras ou até mesmo remoção total do tegumento. Segundo BANZATTO et alii (1975), danos mecânicos no descasque podem ter efeitos imediatos, fazendo decrescer a germinação $\mathrm{e}$ $o$ vigor de sementes de mamona.

A deterioração de tais sementes é especialmẹnte importante, pelo seu alto conteúdo de triglicerfdios. Durante esse processo, as gorduras presentes na semente sofrem alteraçбes por vias oxidativas e, principalmente, hidrolíticas. Essa última via, mediada por lipases, resulta na produção de ácidos graxos livres. A semente de mamona é particularmente rica em lipases (BONNER, 1950; DAVIES et alii, 1969). POMERANZ (1974) afirma que essas alteraçס̃es são grandemente aceleradas pela presença de fungos cuja atividade lipolítica é alta.

As sementes dessa oleaginosa, principalmente aquelas descascadas mecanicamente, não se conservam bem em condiçôs normais de armazém. No plantio, é recomendada a colocação de três-quatro sementes por cova; mesmo assim, é freqüente a ocorrência de falhas conseqüentes à utilização de sementes deterioradas.

O objetivo deste trabalho foi estudar a gradual deterioração de sementes de mamona armazenadas sem casca (método convencional) e com 
casca, ou seja, ainda envoltas pelas paredes do fruto e, portanto, sem danos mecânicos provenientes do descasque prévio.

\section{MATERIAL E MÉTỌDOS}

$\mathrm{Na}$ época usual de maturação, foram colhidos frutos de mamona (Ricinus communis L.) dos cultivares indeiscentes Campinas e Guarani e do deiscente IAC-38. Após secagem ao sol, cada porção de frutos de 'Campinas' e 'Guarani' foi dividida em duas subporçðes, sendo uma delas descascada mecanicamente e, a outra, mantida intacta, com as sementes envoltas pelo pericarpo (casca). As sementes do 'IAC-38' separaram-se espontaneamente dos frutos, dispensando o descasque, sem sofrer, portanto, as injurias que ocorrem nessa operação.

Após as determinaçðes iniciais, as sementes ou frutos foram acondicionados em sacos de pano e armazenados em condiçбes normais de armazém no Centro Experimental de Campinas, do Instituto Agronômico.

Cada porção relativa a um tratamento continha cerca de $15 \mathrm{~kg}$ de sementes e, no caso daquelas envoltas pelas paredes do fruto, a composição aproximada foi $40 \%$ de tri e dicocas e $60 \%$ de monococas.

A deterioração das sementes foi avaliada por testes de germinação e umidade realizados a cada três meses e por análise química de óleo e ácidos graxos livres ao fim dos 36 meses de armazenamento. Os testes seguiram as prescriçðes das Regras para Análise de Sementes (BRASIL, 1976), com a exceção de que, nos primeiros, foram usadas quatro repetiçoes de 50 sementes cada uma em vez de quatro de 100 sementes cada uma.

$\mathrm{Na}$ determinação do teor de oleo, as sementes foram moídas em almofariz na presença de areia fina e lavada. Em seguida, o material homogeneizado foi transferido para extrator Soxhlet, onde os lipídios foram extraídos a quente, utilizando-se como solvente o álcool etílico $99^{\circ} \mathrm{GL}$, em extração contínua por seis horas. A avaliação do teor de óleo extraído foi gravimétrica (BOLLIGER, 1938).

O procedimento usado para a determinação do teor de ácidos graxos livres foi o seguinte: $10 \mathrm{~g}$ do oleo foram transferidos para Erlenmeyer, adicionando-se álcool etílico $95 \%$ neutralizado previamente em álcali, e $2 \mathrm{ml}$ de solução do indicador fenolftaleína a $1 \% \mathrm{em}$ álcool etílico 95\%. A titulação foi feita em álcali, $\mathrm{NaOH} 0,25 \mathrm{~N}$, agitando-se fortemente até cor rósea persistente por pelo menos 30 segundos. Os resultados foram expressos em porcentagem de ácidos graxos livres como ácido oléico (AMERICAN OIL CHEMIST'S SOCIETY, 1975),

No início do experimento, foi feita também a avaliação đo peso hectolitrico, em quilograma/100 litros, por meio de balança especial (BRA- 
SIL, 1976), utilizando-se duas repetiçסes de $250 \mathrm{ml}$ cada uma. Com os mesmos dados, calculou-se o volume por peso, em metro cábico/tonelada.

Imediatamente antes dos testes de germinação e análise química, as sementes armazenadas com casca foram descascadas manualmente.

\section{RESULTADOS E DISCUSSÃO}

As médias mensais de temperatura e umidade relativa ambientes (RESENHAS, 1975/76, 1977/78) observadas no Centro Experimental de Campinas durante a realizaçðo do experimento (janeiro/75-dezembro/77) estão expostas no quadro 1.

QUADRO 1 - Médias mensais de temperatura (T) e umidade relativa (UR) ambientes observadas no Centro Experimental de Campinas durante a realização do experimento (janeiro/1975-dezembro/1977)

\begin{tabular}{|c|c|c|c|c|c|c|}
\hline \multirow{2}{*}{ Mês } & \multicolumn{2}{|c|}{1975} & \multicolumn{2}{|c|}{1976} & \multicolumn{2}{|c|}{1977} \\
\hline & $\mathrm{T}$ & UR & $\mathrm{T}$ & UR & $\mathrm{T}$ & UR \\
\hline & ${ }^{\circ} \mathrm{C}$ & $\%$ & ${ }^{\circ} \mathrm{C}$ & $\%$ & ${ }^{\circ} \mathrm{C}$ & $\%$ \\
\hline$\ldots \ldots$ & 22,2 & 77,3 & 23,1 & 79,4 & 22,9 & 79,5 \\
\hline Fevereiro $\ldots \ldots$ & 23,2 & 81,6 & 21,6 & 81,0 & 24,9 & 68,6 \\
\hline Março . . . . . . . . & 23,4 & 73,0 & 22,5 & 76,3 & 23,6 & 75,5 \\
\hline Abril $\ldots \ldots \ldots$ & 20,1 & 72,4 & 20,4 & 75,8 & 20,7 & 77,9 \\
\hline Maio ... & 17,9 & 71,3 & 17,8 & 79,5 & 18,5 & 72,0 \\
\hline Junho . . . . . . . & 17,5 & 67,8 & 16,5 & 72,9 & 18,6 & 73,8 \\
\hline Julho . . . . . . & 15,7 & 66,1 & 16,1 & 72,3 & 19,6 & 61,7 \\
\hline Agosto ........ & 21,3 & 55,0 & 18,3 & 69,8 & 20,2 & 62,3 \\
\hline Setembro....... & 21,5 & 61,0 & 18,3 & 75,8 & 20,7 & 65,8 \\
\hline Outubro. & 21,0 & 70,0 & 19,7 & 71,2 & 22,8 & 65,8 \\
\hline Novembro . . . . . . & 21,1 & 75,4 & 21,8 & 72,4 & 22,2 & 76,2 \\
\hline Dezembro . . . . . . & 23,1 & 74,9 & 22,1 & 80,5 & 21,5 & 76,0 \\
\hline
\end{tabular}

No quadro 2 estão contidos os dados de germinação e umidade. Verifica-se que o processo de deterioração das sementes armazenadas com casca foi mais lento que o 'daquelas armazenadas sem casca. As sementes dos cultivares Campinas e Guarani, quando mantidas envoltas pelo pericarpo, apresentaram germinação acima de $70 \%$ até os 21 meses, enquanto aquelas sem casca só o fizerem até os 9 meses. 


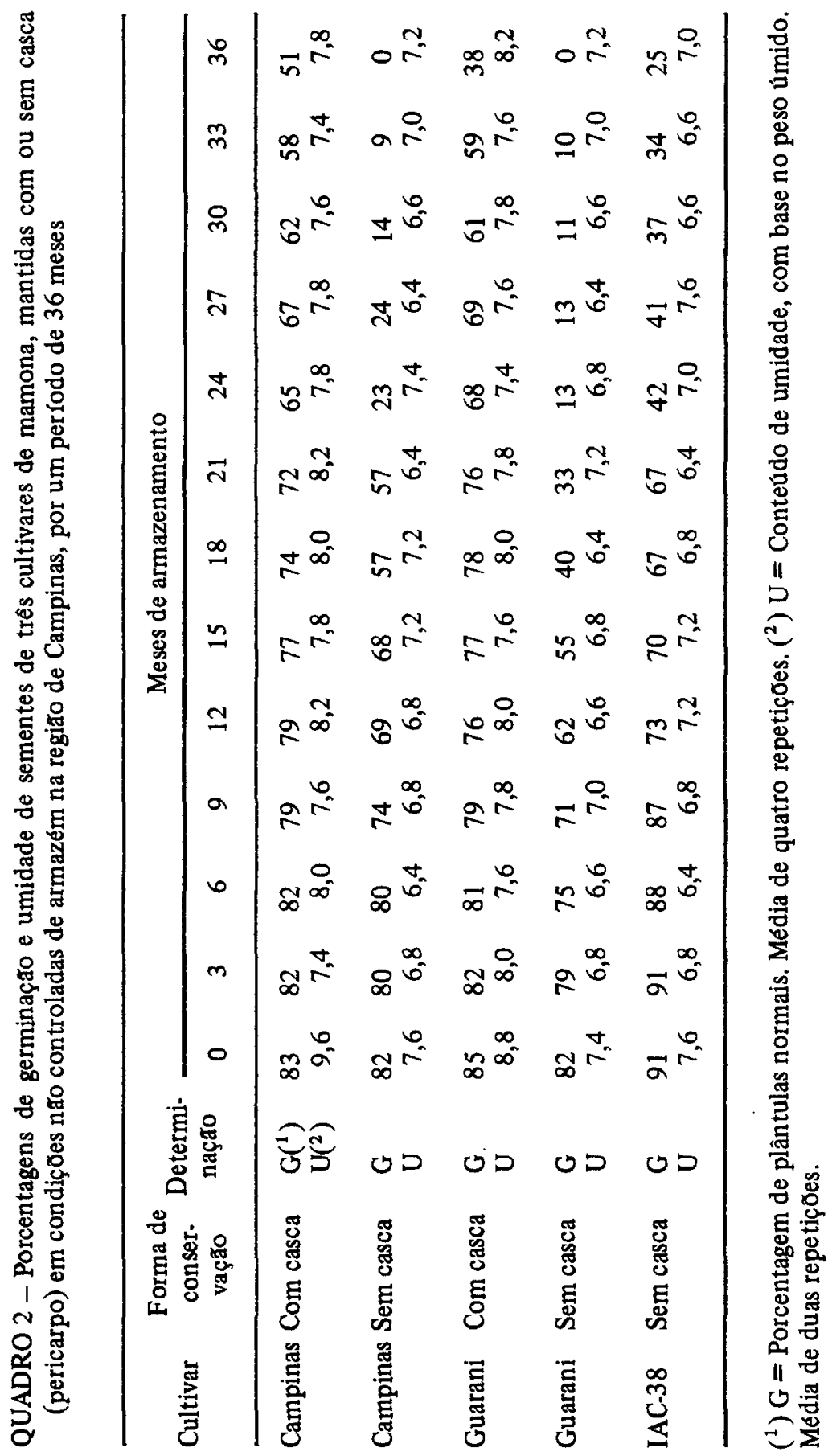


Aos seis meses, caso de sementes armazenadas e plantadas no mesmo ano em que sạ̃o colhidas, as sementes de 'Campinas' e 'Guarani', com ou sem casca, exibiram porcentagens semelhantes de germinação, que variaram de 75 a 82 , não havendo, então, até aquele período, vantagem significativa das sementes com casca. Com o passar do tempo, porém, a vantagem a favor das sementes com casca foi aumentando e, aos 18 meses, caso de sementes armazenadas de um ano para outro, as porcentagens de germinação das sementes com casca foram nitidamente superiores.

Deve-se ressaltar que, uma vez que sementes de mamona são, de qualquer forma, descascadas antes do plantio, as armazenadas com casca sofreriam os danos mecânicos dessa operaçao, com algum possível decréscimo imediato na germinação, como já foi relatado por BANZATTO et alii (1975).

Aos 36 meses, a germinação das sementes com casca de 'Campinas' e "Guarani" foi $51 \%$ e $38 \%$ respectivamente, enquanto aquelas sem casca, de ambos os cultivares, tiveram germinação nula.

As sementes do cultivar de frutos deiscentes 'IAC-38', armazenadas sem casca e sem danos mecânicos, mostraram maior longevidade do que aquelas sem casca dos outros cultivares, com germinação de $70 \%$ ou acima até os 15 meses.

No transcorrer dos 36 meses de armazenamento, o conteúdo de umidade das sementes com casca variou de $9,6 \%$ a $7,4 \%$, com média de $7,9 \%$, enquanto o das sementes sem casca variou de $7,6 \%$ a $6,4 \%$, com média de 6,9\% (Quadro 2). Portanto, o conteúdo de umidade das sementes envoltas pela casca (semente + pericarpo) foi, em média, uma unidade percentual mais alta do que o das sementes propriamente ditas. Isso se deveu, provavelmente, a ter a parede do fruto absorvido proporcionalmente mais umidade do que a semente oleaginosa, que é pouco higroscopica, em seu interior. Diferença de higroscopicidade entre casca e semente, com a primeira retendo mais umidade já foi verificada em amendoim, outra semente pouco higroscópica, por SAISAWAT (1980) e Karon \& Hillery, citados por POMERANZ (1974).

Dentro de um mesmo tipo de semente (com ou sem casca) as diferenças de conteúdo de umidade não foram significativas, não sendo responsáveis por diferenças em velocidade de deterioração entre cultivares.

$O$ peso hectolítrico médio das sementes com casca foi $26,6 \mathrm{~kg}$, aproximadamente a metade do daquelas sem casca, 51,7kg (Quadro 3). Como. conseqüência, o volume por peso, em metro cubico/tonelada, de sementes com casca foi, em média, o dobro do daquelas sem casca, ou seja, $3,8 \mathrm{~m}^{3}$ e $1,9 \mathrm{~m}^{3}$ respectivamente (Quadro 3 ). Tais dados são apenas indicativos, pois variam, principalmente quanto às proporçðes de impurezas, sementes chochas, frutos in teiros (tricocas), dicocas e monococas. De qualquer forma, o 
maior volume por peso representa uma desvantagem, pois, tomando como exemplo os dados do experimento, no armazenamento de determinado peso de material a granel, as sementes com casca exigiram o dobro de espaço no armazém.

QUADRO 3 - Resultados das determinaçós físicas e químicas realizadas em sementes de três cultivares de mamona, mantidos com ou sem casca (pericarpo) em condições não controladas de armazém na região de Campinas, por um perfodo de 36 meses

\begin{tabular}{|c|c|c|c|c|c|}
\hline \multirow{2}{*}{ Cultivar } & \multirow{2}{*}{$\begin{array}{l}\text { Forma de } \\
\text { conservação }\end{array}$} & \multicolumn{2}{|c|}{$\begin{array}{c}\text { Determinaçoes frsicas } \\
\text { a zero mês } \\
(1)\end{array}$} & \multicolumn{2}{|c|}{$\begin{array}{c}\text { Determinaçסes quimicas } \\
\text { aos } 36 \text { meses }\end{array}$} \\
\hline & & $\begin{array}{l}\text { Peso hecto- } \\
\text { lítrico }\end{array}$ & Volume/Peso & Oleo (2) & $\begin{array}{l}\text { Ácidos graxos } \\
\text { livres (1) }\end{array}$ \\
\hline & & $\mathrm{kg} / 100$ litros & $\mathrm{m}^{3} / \mathrm{t}$ & \% M.S. & \% Äcido oléico \\
\hline Campinas & Com casca & 28,0 & 3,6 & 56,9 & 1,6 \\
\hline Campinas & Sem casca & 52,1 & 1,9 & 54,0 & 63,0 \\
\hline Guarani & Com casca & 25,3 & 4,0 & 53,3 & 3,2 \\
\hline Guarani & Sem casca & 50,4 & 2,0 & 48,7 & 64,8 \\
\hline IAC-38 & Sem casca & 52,6 & 1,9 & 48,5 & 19,6 \\
\hline
\end{tabular}

$\left({ }^{1}\right)$ Média de duas repetições. $\left({ }^{2}\right)$ Média de quatro repetições.

O teor de óleo aos 36 meses esteve entre $48,5 \%$ e 56,9\%, sendo que, para 0 mesmo cultivar, as sementes armazenadas com casca apresentaram porcentagens um pouco mais altas do que as daquelas sem casca (Quadro 3).

Diferenças marcantes ocorreram, porém, quanto ao teor de ácidos graxos livres (Quadro 3). As sementes dos cultivares Campinas e Guarani, mantidas na casca, exibiram teores de ácidos graxos de $1,6 \%$ e 3,2\% respectivamente, enquanto, descascadas mecanicamente e assim armazenadas, apresentaram os teores respectivos de $63,0 \%$ e $64,8 \%$. Esses altos teores evidenciam hidrólise intensa dos triglicerf́dios, resultante da ação de lipases que ocorrem em concentração muito alta em sementes de mamona, como revelam DAVIES et alii (1969) e BONNER (1950).

As sementes do cultivar deiscente IAC-38 apresentaram teor intermediário de ácidos graxos, $19,6 \%$. 
Comparando os dados dos quadros 2 e 3, verifica-se que, aos 36 meses, quanto maior o teor de ácidos graxos livres, menor a porcentagem de germinação, ocorrendo, então, uma relação inversa entre esses dois parâmetros, resultante da deterioração e conseqüente formação de ácidos graxos a partir dos triglicerídios existentes na semente. Por essa razão, o teor de ácidos graxos livres tem sido proposto como uma medida do grau de deterioração de sementes e grãos (DELOUCHE et alii, 1962; POMERANZ, 1974).

\title{
SUMMARY \\ DETERIORATION OF SHELLED AND NOT SHELLED CASTORBEAN SEEDS DURING STORAGE
}

\begin{abstract}
Shelled (conventional method) and not shelled (free of mechanical damage from the shelling) castorbean seeds were stored under uncontrolled conditions at Campinas, State of Sao Paulo, Brazil, for periods up to 36 months. The progress of deterioration was evaluated by the standard germination tests at three-month intervals, and by the oil and free fatty acid content at 36 months. Shelled seeds deteriorated faster than those stored with the shells, mainly after the first year. Seeds of the Campinas cultivar, stored not shelled and shelled, presented, after $0,6,12,24$, and 36 months, germination of respectively 83 and $82 \%, 82$ and $80 \%, 79$ and $69 \%, 65$ and $23 \%$, and 51 and $0 \%$. Not shelled and shelled seeds of the Guarani cultivar exhibited seeds germination of respectively 85 and $82 \%, 81$ and $75 \%, 76$ and $62 \%, 68$ and $13 \%$, and 38 and $0 \%$, after the same storage periods. After 36 months of storage, the free fatty acid contents for not shelled seeds of 'Campinas' and 'Guarani' cultivars were respectively, 1.6 and $3.2 \%$, whereas for shelled seeds of the same cultivars, the contents were 63.0 and $64.8 \%$, respectively.
\end{abstract}

Index terms: deterioration, storage, seeds, castorbean, cultivars Campinas and Guarani.

\section{REFERÊNCIAS BIBLIOGRÁFICAS}

AMERICAN OIL CHEMIST'S SOCIETY. Official and tentative methods. Free Fatty Acids, AOCS Official Methods Aa 6-33. 3.ed.rev. Edited by W.E. Link. Illinois, 1975.

BACCHI, O. \& CANECCHIO FILHO, V. A desinfecção de sementes de amendoim. Bragantia, Campinas, 14:1-11, 1954.

BANZATTO, N. V.; ZINK, E. \& SAVY FILHO, A. Estudos preliminares sobre sementes de mamoneira (Ricinus communis L.). Semente, Brasília, 1(1):31-36, 1975.

BASKIN, C. C. \& DELOUCHE, J. C. Effects of mechanical shelling on storability of peanut (Arachis hypogaea L.) seed. Proceedings of the Association of Official Seed Analyst, 61:78-84, 1971. 
BOLLIGER, R. Método rápido para a dosagem de óleo nas sementes oleaginosas (tungue e mamona). Campinas, Instituto Agronômico, 1938. 12p. (Boletim Técnico, 43)

BONNER, J. Plant Biochemistry. New York, Academic Press, 1950. 537p.

BRASIL. Ministério da Agricultura. Divisão de Sementes e Mudas. Regras para análise de sementes. Brasília, 1976. 188p.

DAVIES, D. D.; GIOVANELLI, J. \& REES, T. A. Bioquímica vegetal. Barcelona, Ediciones Omega, 1969. 504p.

DELOUCHE, J. C.; STILL, T. W.; RASPET, M. \& LIENHARD, M. The tetrazolium test for seed viability. Miss. State, Mississippi State University, Agricultural Experiment Station, 1962. 64p. (Technical Bulletin, 51)

JUSTICE, O. L. \& BASS, L. N. Principles and practices of seed storage. Washington, U.S.D.A., 1978. 289p. (Agriculture Handbook, 506)

LINK, W. E. Official and tentative methods. 3.ed. rev. Illinois, American Oil Chemi St'S Society, 1975. (AOCS Official Methods Aci 6-33). 6-33).

MOORE, R. P. Effects of mechanical injuries on viability. In:ROBERTS, E. H., ed. Viability of seeds, Syracuse, University Press, 1972: p.94-113.

POMERANZ, Y. Biochemical, functional, and nutritive changes during storage. In: CHRISTENSEN, C. M., ed. Storage of cereal grains and their products. St. Paul, Am. Ass. Cereal Chemists, 1974. p.56-114.

POPINIGIS, F. Immediate effects of mechanical injury on soybean. Mississippi State, Mississippi State University, 1972. 75p. Tese. (Mestrado)

RESENHAS meteorologicas. O Agronômico, Campinas, 27/28:401-448, $1975 / 76 ; 29 / 30: 311-336,1977 / 78$.

SAISAWAT, P. Functional aspects of peanut (Arachis hypogaea L.) fruit and seed maturation. Mississippi Stạte University, 1980. 109p. Tese. (Doutorado)

ZINK, E. Immediate and latent effects of mechanical abuse on the germination of soybean seed. Mississippi State, Mississippi State University, 1966. 55p. Tese. (Mestrado)

; CORAL, F. J. \& TELLA, R. Estudos sobre a conservação de sementes. X. Amendoim. Bragantia, Campinas, 21 :CLIX-CLVX, 1962. (Nota, 27) 